\title{
Article \\ Growth Hormone (GH) Treatment Decreases Plasma Kisspeptin Levels in GH-Deficient Adults with Prader-Willi Syndrome
}

\author{
Olga Giménez-Palop ${ }^{1,2,3,+}$, Laia Casamitjana ${ }^{1,2,3,+}$, Raquel Corripio ${ }^{2,3,4}\left(\mathbb{D}\right.$, Susanna Esteba-Castillo ${ }^{5,6}$, \\ Rocío Pareja ${ }^{1,2}$, Néstor Albiñana ${ }^{2}$, Mercedes Rigla 1,2,3 and Assumpta Caixàs 1,2,3,*
}

1 Endocrinology and Nutrition Department, Hospital Universitari Parc Taulí, 08208 Sabadell, Spain; ogimenez@tauli.cat (O.G.-P.); lcasamitjana@tauli.cat (L.C.); rpareja@tauli.cat (R.P.); mrigla@tauli.cat (M.R.)

2 Institut d'Investigació i Innovació Parc Taulí (I3PT), 08208 Sabadell, Spain; rcorripio@tauli.cat (R.C.); nalbinana@tauli.cat (N.A.)

3 Department of Medicine, Universitat Autònoma de Barcelona, 08208 Sabadell, Spain

4 Pediatrics Department, Hospital Universitari Parc Taulí, 08208 Sabadell, Spain

5 Specialized Service in Mental Health and Intellectual Disability, Institut Assistència Sanitària (IAS), Parc Hospitalari Martí i Julià, 17190 Salt, Spain; susanna.esteba@ias.cat

6 Neurodevelopment Group (Girona Biomedical Research Institute)_IDIBGI, Institute of Health Assistance (IAS), Parc Hospitalari Martí i Julià, 17190 Salt, Spain

* Correspondence: acaixas@tauli.cat

+ Both authors contributed equally.

\section{check for} updates

Citation: Giménez-Palop, O.; Casamitjana, L.; Corripio, R.; Esteba-Castillo, S.; Pareja, R.; Albiñana, N.; Rigla, M.; Caixàs, A. Growth Hormone (GH) Treatment Decreases Plasma Kisspeptin Levels in GH-Deficient Adults with Prader-Willi Syndrome. J. Clin. Med. 2021, 10, 3054. https://doi.org/ $10.3390 /$ jcm10143054

Academic Editor: Claudia Giavoli

Received: 12 June 2021

Accepted: 8 July 2021

Published: 9 July 2021

Publisher's Note: MDPI stays neutral with regard to jurisdictional claims in published maps and institutional affiliations.

Copyright: (c) 2021 by the authors. Licensee MDPI, Basel, Switzerland. This article is an open access article distributed under the terms and conditions of the Creative Commons Attribution (CC BY) license (https:/ / creativecommons.org/licenses/by/ $4.0 /)$.

\begin{abstract}
Obesity and growth hormone (GH)-deficiency are consistent features of Prader-Willi syndrome (PWS). Centrally, kisspeptin is involved in regulating reproductive function and can stimulate hypothalamic hormones such as GH. Peripherally, kisspeptin signaling influences energy and metabolic status. We evaluated the effect of 12-month GH treatment on plasma kisspeptin levels in 27 GH-deficient adult PWS patients and analyzed its relationship with metabolic and anthropometric changes. Twenty-seven matched obese subjects and 22 healthy subjects were also studied. Before treatment, plasma kisspeptin concentrations in PWS and obese subjects were similar (140.20 (23.5-156.8) pg/mL vs. $141.96(113.9-165.6) \mathrm{pg} / \mathrm{mL}$, respectively, $p=0.979))$ and higher $(p=0.019)$ than in healthy subjects (124.58 (107.3-139.0) pg/mL); plasma leptin concentrations were similar in PWS and obese subjects (48.15 (28.80-67.10) ng/mL vs. 33.10 (20.50-67.30) ng/mL, respectively, $p=0.152)$ and higher $(p<0.001)$ than in healthy subjects $(14.80(11.37-67.30) \mathrm{ng} / \mathrm{mL})$. After GH therapy, lean body mass increased $2.1 \%(p=0.03)$, total fat mass decreased $1.6 \%(p=0.005)$, and plasma kisspeptin decreased to levels observed in normal-weight subjects (125.1(106.2-153.4) pg/mL, $p=0.027)$. BMI and leptin levels remained unchanged. In conclusion, 12-month GH therapy improved body composition and decreased plasma kisspeptin in GH deficient adults with PWS. All data are expressed in median (interquartile range).
\end{abstract}

Keywords: Prader-Willi Syndrome; kisspeptin; leptin; growth hormone deficiency

\section{Introduction}

Kisspeptin is a hormone that promotes the onset of puberty by stimulating the secretion of gonadotropin-stimulating hormone $(\mathrm{GnRH})$. Kisspeptin can also stimulate the release of other pituitary hormones such as prolactin, growth hormone (GH), oxytocin, and vasopressin [1].

Kisspeptin is mainly synthesized by neurons in the arcuate nucleus of the hypothalamus. Its synthesis is modulated by energy balance, decreasing in situations of insufficient weight (e.g., anorexia nervosa) or excess weight (e.g., obesity) [2]. Low kisspeptin levels are considered the cause of the hypogonadotropic hypogonadism seen in some patients with metabolic syndrome and obesity $[2,3]$.

Kisspeptin-producing neurons express receptors for leptin, a hormone produced in adipose tissue that informs these neurons about the status of energy reserves $[4,5]$. 
Kisspeptin is also expressed in peripheral tissues involved in metabolic functions such as the pancreas, liver, and adipose tissue, and emerging data suggests peripheral kisspeptin plays a role in the regulation of insulin secretion [6].

Prader-Willi Syndrome (PWS) is a rare genetic disease characterized by a series of disorders of hypothalamic functionalism: hyperphagia, obesity, hypogonadotropic hypogonadism, short stature due to GH deficiency [7-9], and cognitive, praxis, and behavioral disorders [10-12]. Up to $60 \%$ of adults with PWS have GH deficiency [13], which results in decreased muscle mass and strength and increased fat mass [14]. These changes can be mitigated with GH treatment, which induces metabolically beneficial changes in body composition [15,16].

Kisspeptin concentrations are decreased in patients with idiopathic hypogonadotropic hypogonadism, diabetes, or metabolic syndrome [2,4,5]. To our knowledge, kisspeptin has not been studied in patients with PWS; however, since these patients have impaired hypothalamic function, obesity (often associated with diabetes), central hypogonadism, and GH deficiency, they would be expected to have decreased kisspeptin levels. Moreover, it remains to be determined whether $\mathrm{GH}$ treatment could influence kisspeptin synthesis directly through a negative feedback mechanism or indirectly through changes in body composition.

We aimed to determine changes in plasma kisspeptin concentrations in 27 adult patients with PWS after 12 months of GH treatment and whether these changes are associated with changes in anthropometric or metabolic parameters.

\section{Materials and Methods}

\subsection{Subjects}

We included 27 adults with PWS (15 women, median age: 26 years, range: 18-53) treated at our center between 1 January 2016 and 31 January 2019. Cytogenetic analysis revealed 7 had type 1 deletion, 10 had type 2 deletion, 6 had maternal uniparental disomy, 3 had imprinting defects and 1 had an atypical BP2-BP4 microdeletion. All had GH deficiency diagnosed with GHRH-arginine and/or glucagon stimulation tests [17-19]. The cut off for GH deficiency with GHRH-arginine test was: $\mathrm{GH}<11 \mathrm{ng} / \mathrm{mL}$ if BMI $<25 \mathrm{~kg} / \mathrm{m}^{2}$, $<8 \mathrm{ng} / \mathrm{mL}$ if BMI $25-30 \mathrm{~kg} / \mathrm{m}^{2}$, and $<4 \mathrm{ng} / \mathrm{mL}$ if BMI $\geq 30 \mathrm{~kg} / \mathrm{m}^{2}$. The cut off for glucagon test was $\mathrm{GH}<3 \mathrm{ng} / \mathrm{mL}$ at any time point.

Six patients had type 2 diabetes with good glycemic control $(\mathrm{HbA} 1 \mathrm{c}<7.5 \%)$ and 15 (7 women) were receiving sex steroids. None had precocious puberty. For comparison, we also evaluated 27 obese subjects matched for age, sex, and BMI and 22 healthy subjects.

The study complied with all provisions in the Declaration of Helsinki and was approved by the local ethics committee (Comitè d'Ėtica d'Investigació amb medicaments del Parc Taulí). All patients with PWS agreed to participate after being informed together with their parents or caregivers; their legal guardians (usually their parents) signed the consent form before enrollment. All control participants provided written informed consent.

\subsection{Methods}

Blood was extracted from all participants at $8 \mathrm{AM}$ after overnight fasting. Plasma samples for kisspeptin and leptin measurements were kept at $-80^{\circ} \mathrm{C}$ until analysis. We recorded subjects' height, determined by a stadiometer (Harpenden, Holtain Ltd., Dyfed, $\mathrm{UK}$; body weight, measured to the nearest $0.1 \mathrm{~kg}$ with standard equipment; body mass index (BMI); and body composition determined by dual-energy x-ray absorptiometry (Lunar Prodigy-963, Chicago, IL, USA).

To determine concentrations of kisspeptin-1 in plasma, we used the Kisspeptin-1 ELISA kit (Cloud-Clone Corp., Houston, TX, USA) (lower limit of detection, $9.27 \mathrm{pg} / \mathrm{mL}$; intraassay coefficient of variation $(\mathrm{CV})<10 \%$; interassay $\mathrm{CV}<12 \%)$. To determine concentrations of leptin in plasma, we used the Human Leptin ELISA Kit (Biorbyt, Cambridge, UK) (lower limit of detection, $10 \mathrm{pg} / \mathrm{mL}$; intraassay $\mathrm{CV}<7.6 \%$; interassay $\mathrm{CV}<8.4 \%$ ). A routine automated analyzer was used for other laboratory tests. The homeostatic model as- 
sessment for insulin resistance (HOMA-IR) index was calculated as fasting plasma glucose $(\mathrm{mmol} / \mathrm{L}) \times$ fasting insulin $(\mu \mathrm{IU} / \mathrm{mL}) / 22.5$ [20].

Patients with PWS were treated with recombinant GH (Genotonorm Miniquick ${ }^{\circledR}$, Pfizer, New York, NY, USA), starting with a dose of $0.2 \mathrm{mg} /$ day and adjusting the dose at $1,3,6$, and 12 months to achieve high-normal insulin-like growth factor-1 (IGF-1) levels for the patient's age.

Only PWS patients received GH treatment. After 12 months' GH treatment, patients' analytic and anthropometric parameters were measured again with the same protocol.

\subsection{Statistical Analyses}

Continuous variables are reported as medians and interquartile ranges (IQR). Categorical variables are reported as frequencies and percentages. To compare all the continuous variables at baseline, between the 3 groups, we used Kruskal-Wallis test followed by the Mann-Whitney U test with Bonferroni correction. To compare all variables before and after GH treatment we used the Wilcoxon signed-rank test. To study the relationship between variables, we used Spearman's rank-order correlation test. Statistical significance was fixed at $p<0.05$. All analyses were done with IBM SPSS Statistics for Windows, version 25.0 (IBM Corp., Armonk, NY, USA).

\section{Results}

\subsection{Baseline Findings}

\subsubsection{Patient Characteristics}

Table 1 reports the baseline characteristics of subjects in the PWS, obese, and normal weight groups. The PWS and obese groups did not differ in weight, BMI, waist, percentages of body fat and lean mass, glucose, HOMA-IR, follicle-stimulating hormone, or testosterone (only measured in men) levels. Females in the PWS group had lower levels of estradiol and luteinizing hormone than females in the obese group.

Table 1. Baseline characteristics of participants.

\begin{tabular}{|c|c|c|c|c|}
\hline & PWS Patients $(n=27)$ & Obese Subjects $(n=27)$ & Healthy Subjects $(n=22)$ & $p$-Value \\
\hline Sex (female) & $15(55.6 \%)$ & $15(55.6 \%)$ & $11(50 \%)$ & *0.907 \\
\hline Age (years) & $26(24-37)$ & $28(24-37)$ & $27.5(21.5-37.5)$ & *0.909 \\
\hline Weight (kg) & $89.6(70.5-105.5)$ & $95.5(81.8-121.1)$ & $65.8(58.1-71.6)$ & $\begin{aligned} * & <0.001 \\
& +0.135 \\
\lambda & <0.001 \\
& <0.001\end{aligned}$ \\
\hline Height $(\mathrm{cm})$ & $156(148.0-165.0)$ & $169(162.0-173.0)$ & $169(164.5-181.5)$ & $\begin{array}{l}*<0.001 \\
\dagger<0.001 \\
\lambda<0.001 \\
* * 0.344\end{array}$ \\
\hline BMI $\left(\mathrm{kg} / \mathrm{m}^{2}\right)$ & $34.6(30.9-41.3)$ & $32.1(29.3-41.9)$ & $22.2(20.9-22.9)$ & $\begin{aligned} * & <0.001 \\
& \dagger 0.580 \\
\lambda & <0.001 \\
& <0.001\end{aligned}$ \\
\hline Waist (cm) & $110.0(101.0-124.0)$ & $107.0(99.0-121.0)$ & 78.5 (71.5-83.7) & $\begin{array}{c}*<0.001 \\
+0.387 \\
\lambda<0.001 \text { ** } \\
<0.001\end{array}$ \\
\hline
\end{tabular}


Table 1. Cont.

\begin{tabular}{|c|c|c|c|c|}
\hline & PWS Patients $(n=27)$ & Obese Subjects $(n=27)$ & Healthy Subjects $(n=22)$ & $p$-Value \\
\hline Glucose (mmol/L) & $5.00(4.55-6.99)$ & $4.83(4.77-5.49)$ & $4.36(4.16-5.02)$ & $\begin{array}{c}* 0.006 \\
+0.827 \\
\lambda 0.004^{* *} \\
0.006\end{array}$ \\
\hline HOMA-IR & $2.26(1.52-4.80)$ & $2.58(1.79-3.96)$ & $1.37(0.84-1.84)$ & $\begin{array}{c}*<0.001 \\
+0.710 \\
\lambda 0.001 \text { ** } \\
<0.001\end{array}$ \\
\hline IGF-I (ng/mL) & $143.0(95.0-188.0)$ & $171(139.5-257.5)$ & $226.0(192.7-312.0)$ & $\begin{array}{c}*<0.001 \\
t^{*}=0.007 \\
\lambda<0.001 \text { ** } \\
0.084\end{array}$ \\
\hline LH (IU/L) & $1.21(0,36-6.29)$ & $6.01(4.1-7.75)$ & $5.48(3.5-12.75)$ & $\begin{array}{c}* 0.001 \\
+0.001 \\
\lambda 0.001 \text { ** } \\
0.947\end{array}$ \\
\hline FSH (IU/L) & $3.63(0.3-7.28)$ & $5.19(2.9-6.76)$ & $3.31(2.3-7.22)$ & *0.301 \\
\hline $\begin{array}{l}\text { Testosterone, in males } \\
\qquad(\mathrm{ng} / \mathrm{mL})\end{array}$ & $2.08(0.51-3.61)$ & $3.82(2.47-4.44)$ & $5.63(4.82-8.11)$ & $\begin{array}{c}{ }^{*}<0.001 \\
+0.75 \\
\lambda<0.001 \\
0.002\end{array}$ \\
\hline $\begin{array}{l}\text { Estradiol, in females } \\
(\mathrm{pg} / \mathrm{mL})\end{array}$ & $23(16-44)$ & $94(60-164)$ & $63(5-168)$ & $\begin{array}{c}{ }^{*} 0.001 \\
><0.001 \\
\lambda 0.253^{* *} \\
0.287\end{array}$ \\
\hline Fat mass $(\%)$ & $56.3(49.3-61.1)$ & $50.8(41.9-61.9)$ & $38.7(28.1-39.5)$ & $\begin{array}{c}*<0.001 \\
+0.640 \\
\lambda<0.001 \text { ** } \\
<0.001\end{array}$ \\
\hline Lean mass (\%) & $43.6(38.9-50.2)$ & $49.2(36.4-51.3)$ & $69.2(56.4-71.8)$ & $\begin{array}{c}*<0.001 \\
+0.891 \\
\lambda<0.001 \text { ** } \\
<0.001\end{array}$ \\
\hline Kisspeptin (pg/mL) & $140.20(123.5-156.8)$ & $141.96(113.9-165.6)$ & $124.58(107.3-139.0)$ & $\begin{array}{c}* 0.094 \\
+0.979 \\
\lambda 0.019 * * \\
0.154\end{array}$ \\
\hline Leptin (ng/mL) & $48.15(28.80-67.10)$ & $33.10(20.50-67.30)$ & $14.8(11.4-67.3)$ & $\begin{array}{c}*<0.001 \\
+0.152 \\
\lambda<0.001 \text { ** } \\
<0.001\end{array}$ \\
\hline
\end{tabular}

PWS = Prader-Willi syndrome; BMI = body mass index; HOMAR-IR = homeostatic model assessment for insulin resistance; $\mathrm{LH}=$ luteinizing hormone; FSH $=$ follicle-stimulating hormone. $p$-values are marked with ${ }^{*}$ Kruskall-Wallis test for comparisons of PWS vs. Obese vs. Healthy. Mann-Whitney U test with Bonferroni correction for the following comparisons: $\uparrow$ PWS vs. Obese, $\lambda$ PWS vs. Healthy, and ${ }^{* *}$ Obese vs. Healthy. All variables except for sex are reported as median (interquartile range). 


\subsubsection{Kisspeptin Levels}

Overall, kisspeptin levels did not differ between sexes (132.9 pg/mL (107.8-161.8) in females vs. $135.3 \mathrm{pg} / \mathrm{mL}(119.9-162.2)$ in males, $p=0.488)$.

In PWS subjects, baseline kisspeptin levels were similar to those in the obese group and higher than those in the healthy group (Table 1, Figure 1). There were no differences between diabetic and non-diabetic subjects (141.1 pg/mL (121.1-152.6) vs. $140.2 \mathrm{pg} / \mathrm{mL}$ (128.2-163.6), respectively, $p=0.798)$. Patients treated with sex steroids had higher levels of kisspeptin (149.4 pg/mL (138.3-165.3) vs. $133.6 \mathrm{pg} / \mathrm{mL}$ (117.8-142.2) than those not treated with sex steroids, $p=0.01)$, but these two groups did not differ in terms of BMI ( $p=0.981)$, testosterone levels in men, or estradiol levels in women (data not shown).

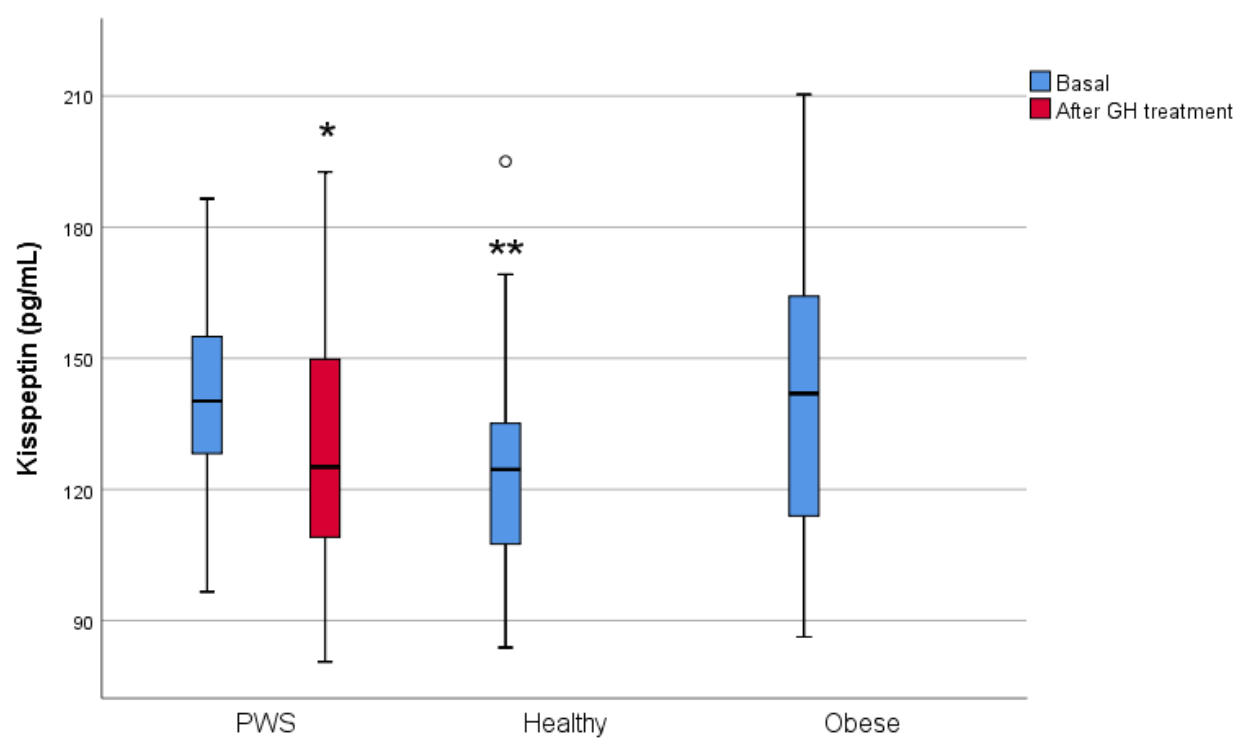

Figure 1. Kisspeptin levels at baseline in the three groups (blue) and after GH treatment in PWS (red). $\mathrm{GH}=$ growth hormone. ${ }^{*}$ Willcoxon signed-rank test, $p=0.027$ between baseline and postGH treatment. ${ }^{* *}$ Mann-Whitney U test with Bonferroni correction, $p=0.019$ between PWS and healthy groups. Outliers are represented as circle symbols.

\subsubsection{Leptin Levels}

Overall, leptin levels were higher in females than in males $(43.95 \mathrm{ng} / \mathrm{mL}(22.75-73.05)$ vs. $22.80 \mathrm{ng} / \mathrm{mL}(11.80-29.50)$ respectively, $p<0.001)$.

In PWS subjects, baseline leptin levels were similar to those in the obese group and higher than those in the healthy group (Table 1, Figure 2). Leptin levels did not differ between diabetic and non-diabetic subjects $(45.30 \mathrm{ng} / \mathrm{mL}(19.60-61.80)$ vs. $51.0 \mathrm{ng} / \mathrm{mL}$ (29.50-82.40), respectively, $p=0.866$ ) or between those treated with sex steroids and those not treated with sex steroids $(51.0 \mathrm{ng} / \mathrm{mL}(31.20-62.0)$ vs. $45.2 .0 \mathrm{ng} / \mathrm{mL}(26.70-82.40)$, respectively, $p=0.919$ ).

\subsection{Comparison between Baseline and Post-GH-Treatment Findings in the PWS Group}

After $\mathrm{GH}$ treatment, no significant changes were observed in anthropometric measures, glucose metabolism, gonadotropins, or sex steroids. As expected, IGF-1 levels increased (143(95-188) ng/mL vs. 217(160-254) ng/mL, $p<0.001$ ) (Table 2). Kisspeptin levels were significantly lower than at baseline $(p=0.027)$ and were similar to those in the healthy group (125.1 pg/mL (106.2-153.4) vs. $124.58 \mathrm{pg} / \mathrm{mL}$ (107.3-139.0), respectively, $p=0.936)$ (Table 2, Figure 1). Body composition improved after treatment: total body fat was $1.6 \%$ lower $(p=0.005)$ and lean body mass was $2.1 \%$ higher $(p=0.005)$ (Table 2$)$. 


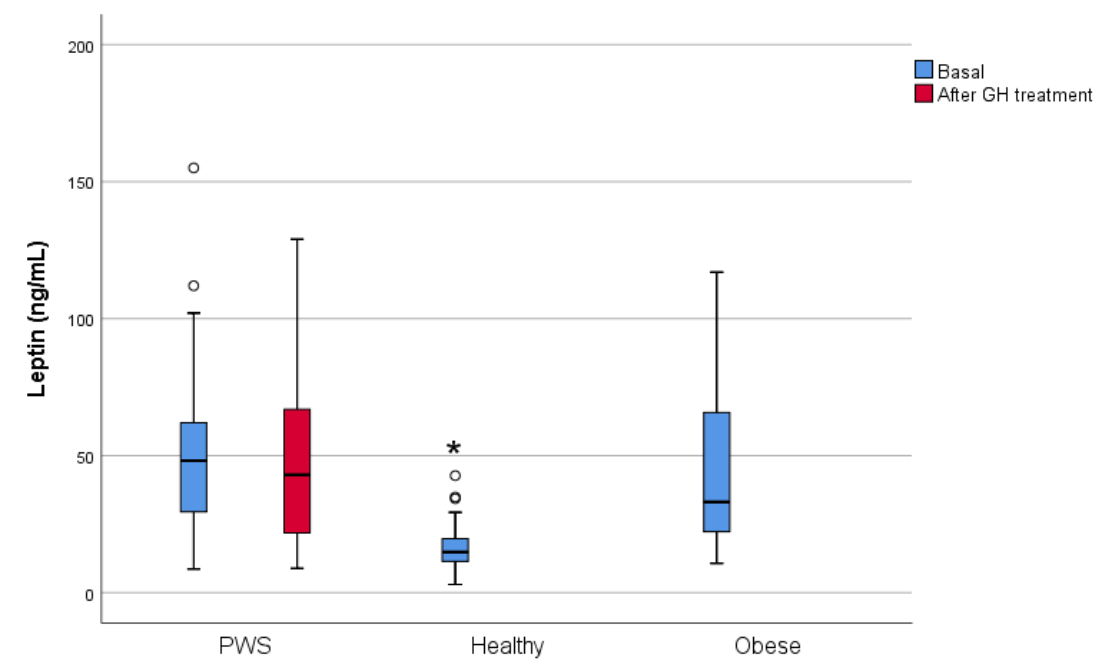

Figure 2. Leptin levels at baseline in the three groups (blue) and after GH treatment in PWS (red). ${ }^{*} p<0.001$ Differences in baseline leptin levels between the three groups (Kruskall-Wallis test). Leptin levels did not change in Prader-Willi subjects after GH treatment (Willcoxon signed-rank test, $p=0.144)$. Outliers are represented as circle symbols.

Table 2. Anthropometrics, body composition, and plasma hormone levels in patients with PWS before and after 12 months' growth hormone treatment.

\begin{tabular}{|c|c|c|c|}
\hline & $\begin{array}{l}\text { Before GH Treatment } \\
\text { Median (IQR) }\end{array}$ & $\begin{array}{c}\text { After } 12 \text { Months' GH Treatment } \\
\text { Median (IQR) }\end{array}$ & $p$-Value * \\
\hline Weight (kg) & $89.6(70.5-105.5)$ & $87.7(74.3-100.2)$ & 0.990 \\
\hline $\operatorname{BMI}\left(\mathrm{kg} / \mathrm{m}^{2}\right)$ & $34.6(30.9-41.3)$ & $34.0(31.8-41.6)$ & 0.692 \\
\hline Waist $(\mathrm{cm})$ & $110.0(101.0-124.0)$ & $112.0(104.0-123.5)$ & 0.602 \\
\hline Glucose (mmol/L) & $5.00(4.55-6.99)$ & $4.83(4.33-5.49)$ & 0.107 \\
\hline HOMA-IR & $2.26(1.52-4.80)$ & $2.95(1.99-6.14)$ & 0.209 \\
\hline HbA1c (\%) & $5.6(5.3-6.9)$ & $5.6(5.3-6.2)$ & 0.294 \\
\hline LH (IU/L) & $1.21(0.36-6.29)$ & $2.71(0.3-5.81)$ & 0.841 \\
\hline FSH (IU/L) & $3.63(0.3-7.28)$ & $5.82(0.92-9.03)$ & 0.015 \\
\hline Testosterone, in males (ng/mL) & $2.08(0.51-3.61)$ & $1.43(0.43-3.22)$ & 0.814 \\
\hline Estradiol, in females (pg/mL) & $23(16-44)$ & $16(8-31)$ & 0.124 \\
\hline IGF-1 (ng/mL) & 143(95-188) & $217(160-254)$ & $<0.001$ \\
\hline Fat mass $(\%)$ & $56.3(49.3-61.1)$ & $52.1(49.9-59.2)$ & 0.028 \\
\hline Lean mass (\%) & $43.6(38.9-50.2)$ & $47.9(40.8-50.1)$ & 0.002 \\
\hline Total body water (kg) & $37.6(32.2-43.0)$ & $37.1(32.9-43.6)$ & 0.342 \\
\hline Extremities/trunk body fat index & $0.92(0.70-1.09)$ & $0.86(0.75-1.11)$ & 0.637 \\
\hline $\begin{array}{l}\text { Appendicular skeletal muscle mass index } \\
\qquad\left(\mathrm{kg} / \mathrm{m}^{2}\right)\end{array}$ & $6.6(5.6-7.7)$ & $7.2(6.1-8.4)$ & 0.059 \\
\hline $\begin{array}{l}\text { Total femur bone mineral density } \\
\text { (Z-score) }\end{array}$ & $-1.31(-1.8-(-0.65))$ & $-1.22(-1.77-(-0.43))$ & 0.485 \\
\hline Total spine bone mineral density Z-score & $-1.61(-2.20-(-0.56))$ & $-1.90(-2.49-(-0.51))$ & 0.927 \\
\hline Kisspeptin (pg/mL) & $140.20(123.5-156.8)$ & $125.1(106.2-153.4)$ & 0.027 \\
\hline Leptin (ng/mL) & $48.15(28.80-67.10)$ & $43.00(21.75-68.32)$ & 0.144 \\
\hline
\end{tabular}

$\mathrm{IQR}$ = interquartile range; $\mathrm{BMI}=$ body mass index; HOMAR-IR = homeostatic model assessment for insulin resistance; $\mathrm{LH}=$ luteinizing hormone; FSH = follicle-stimulating hormone; IGF-1 = insulin-like growth factor-1. ${ }^{*}$ Willcoxon signed-rank test. 
By contrast, leptin levels were not significantly different after treatment (Table 2, Figure 2) and no significant changes in bone mineral density were observed; Z-scores remained lower than expected for age (Table 2).

\section{Correlations}

Overall, baseline kisspeptin did not correlate significantly with weight, BMI, percentage of body fat or total body fat, percentage of lean mass or total lean mass, waist circumference, glucose, insulin, HOMA-IR, glycated hemoglobin, gonadotropins, or sex steroids. Baseline kisspeptin and leptin levels correlated only in the healthy group $(\mathrm{r}=0.414, p=0.05)$.

In the PWS group, baseline kisspeptin did not correlate significantly with any of the above variables or with IGF-1, bone mineral density (total femur Z-score, total spine Z-score), extremities/trunk body fat index, or appendicular skeletal muscle mass index. Moreover, the percentage of change in kisspeptin did not correlate with the percentage of change in body fat (whether measured in \% or $\mathrm{kg}$ ), lean body mass (whether measured in $\%$ or $\mathrm{kg}$ ), HOMA-IR, insulin, glucose, or IGF-1.

Overall, baseline leptin levels correlated with percentage of body fat $(r=0.721$, $p<0.001)$ and total body fat $(\mathrm{r}=0.762, p<0.001)$.

In the PWS group, baseline leptin levels correlated with HOMA-IR $(r=0.317, p=0.006)$, but after GH treatment, leptin levels did not correlate with HOMA-IR $(r=0.110, p=0.602)$. Baseline leptin levels also correlated with percentage of body fat $(\mathrm{r}=0.705, p<0.001)$ and after treatment, with percentage of body fat $(\mathrm{r}=0.692, p<0.001)$, as well as with total body fat $(\mathrm{r}=0.498, p=0.01)$.

The percentage of change in IGF-1 did not correlate with the percentage of change in total body fat or in lean body mass.

\section{Discussion}

To our knowledge, this is the first study to evaluate plasma kisspeptin levels in PWS patients. We found that plasma kisspeptin levels in PWS patients with GH deficiency were similar to those in obese subjects matched by age, sex, and BMI and were higher than those in healthy controls. After 12 months of treatment with GH, plasma kisspeptin levels in PWS patients decreased to levels similar to those observed in healthy subjects.

The relationship between obesity and kisspeptin levels is unclear. Hestiantoro et al. [21] found kisspeptin levels were lower in obese than in normal-weight menopausal women. Pita et al. [22] found kisspeptin levels were higher in obese than in normal-weight prepubertal girls, but similar in obese and normal-weight prepubertal boys. Sitticharoon et al. [23] observed higher kisspeptin levels in obese than in non-obese men. In other studies, this group found no differences in kisspeptin levels between obese and normalweight women [24] or between obese and normal-weight girls with central precocious puberty [25]. Taken together, these findings suggest that kisspeptin levels may be influenced more by hormonal status than by obesity per se. Moreover, kisspeptin levels in women differ across the menstrual cycle, being highest in the luteal phase, followed by the preovulation phase and the follicular phase, suggesting that kisspeptin might play a role in peripheral reproductive regulation [26]. In the present study, kisspeptin levels were higher in obese patients (with or without PWS), but did not differ between sexes. However, all our PWS patients had some degree of hypogonadism, and not all of them were being treated with sex hormones. Furthermore, we did not take women's menstrual phase into account because most of these patients do not ovulate. Nevertheless, kisspeptin levels were higher in those with hormone replacement therapy than in those without, suggesting sex hormones might affect peripheral kisspeptin. These findings are in line with those reported in vitro experiments where estrogens stimulated Kiss-1 gene expression in cultured kisspeptin neurons, suggesting a central interaction between sex hormones and kisspeptin-producing cells [27].

The relationship between kisspeptin and BMI is also unclear. Some studies have found positive correlations. One study in men found that kisspeptin levels correlated positively 
with BMI and weight [23], and another in children found they correlated positively with BMI, weight, and waist circumference [28]. However, other studies have found negative correlations between kisspeptin levels and BMI and waist circumference in non-diabetic men and women [29] and between kisspeptin and BMI in anorectic women [30]. In the present study, we found no correlations between kisspeptin and BMI or waist circumference in the whole group or in the PWS group. Discrepancies between studies might be due to the inaccuracy of BMI and waist circumference as measures of body fat and/or to the heterogeneity and the small size of the cohorts studied.

In the PWS group, GH treatment resulted in a decrease in total body fat and an increase in lean body mass, as reported by other authors [31,32]. Because adipocytes appear to be a source of circulating kisspeptin, we expected decreases in body fat mass to result in decreases in kisspeptin levels. Moreover, adipocytes express the kisspeptin-1 receptor (KISS1R), indicating that kisspeptin secreted by adipose tissue could act as an adipokine or as autocrine/paracrine regulator of adipocyte function [33]. However, we found no correlations between the change in kisspeptin and the change in fat mass, lean mass, extremities/trunk body fat index, or appendicular lean mass index after treatment, suggesting there is no clear relationship between kisspeptin and body composition parameters. Furthermore, kisspeptin appears to regulate $\mathrm{GH}$, but the role of kisspeptin in $\mathrm{GH}$ release remains unclear, especially due to discrepancies between in vivo and in vitro findings [1], although the data suggest that kiss1/KISS1R could play a role in a short or ultra-short feedback loop that regulates the function of somatotrophs [1]. Such a role would help explain why kisspeptin levels decreased in GH-deficient patients with PWS after one year of GH therapy. Nevertheless, we found no correlation between the changes in kisspeptin and IGF-1 levels. Further studies are necessary to test this hypothesis.

Leptin is mainly produced by adipose tissue [34], and its concentration in serum correlates with body energy reserves [35]. Leptin may signal peripheral energy status to the hypothalamus, thus influencing food intake and reproductive function [36]. Kisspeptin neurons in the hypothalamus have leptin receptors, and leptin increases Kiss1 mRNA expression in those neurons, thus supporting the existence of a leptin-kisspeptin-GnRH pathway in which kisspeptin would mediate between energy reserves and the maturation of the hypothalamic-pituitary-gonadal axis [2].

In our study, plasma leptin levels correlated with body fat mass in all groups at baseline, and no significant changes in leptin levels occurred in the PWS group after GH treatment. These findings are in line with those reported by Höybe et al. [37] in 2003 in a study with 17 adult patients with PWS, but discrepant with those reported by Myers et al. [38], who reported decreased leptin levels after GH treatment in children with PWS. Moreover, we found no correlation between plasma leptin and kisspeptin levels, indicating that these two peptides could be less interrelated peripherally than in the central nervous system.

Inactivation of kiss1r in mice results in obesity and diabetic phenotype [39], and kisspeptin and its receptor are expressed in metabolic tissues (e.g., fat, liver and pancreatic tissues) and likely plays a role in regulating insulin secretion. [6]. However, kisspeptin stimulates insulin secretion only when glucose levels are elevated, suggesting kisspeptin's role involves correcting hyperglycemia [40]. Glucagon secreted from pancreatic $\alpha$-cells provokes kiss1 expression in the liver, increasing secretion of kisspeptin from the liver and thereby suppressing glucose-stimulated insulin secretion from pancreatic $\beta$-cells [33].

For all these reasons, we also analyzed the relationship between kisspeptin and glucose metabolism in our cohort of patients with PWS, 6 (22.2\%) of whom had diabetes with good glycemic control ( $\mathrm{HbA} 1 \mathrm{c}<7.5 \%)$. We found no difference in kisspeptin levels between diabetic and non-diabetic PWS patients, and kisspeptin levels did not correlate with plasma glucose, insulin, glycated hemoglobin, or HOMA-IR index. After GH treatment, no changes in these parameters or correlations between these parameters and kisspeptin were observed. These results corroborate those of a previous study that showed no effect of GH treatment on glycemic control in adults with PWS [32]. 
The limitations of our study are mainly due to the characteristics of the sample. The small size of the groups precluded subanalyses by sex or by genetic subtype. Moreover, in both the PWS group and the matched obese controls, obesity was heterogeneous, ranging from low risk (class 1) to high risk (class 3). Only a small proportion of patients were receiving sex hormones, and we did not take the menstrual cycle phase into consideration. All these limitations may have contributed to the lack of significant correlations between variables, and larger studies would be necessary to draw conclusions.

The authors want to emphasize that the recent development of more sensitive methods to detect plasma kisspeptin concentrations leading to better quantitative results instead of undetectable values may have influenced the opposite findings to the initial hypothesis of the present study.

In summary, we found that plasma kisspeptin levels in our cohort of GH-deficient adults with PWS did not differ from those in matched obese patients and were higher than those in a group of normal weight subjects. After one year of GH treatment, kisspeptin levels decreased to levels similar to those in healthy controls. Although the mechanism through which this decrease occurs and its clinical significance remain to be determined, we speculate that GH treatment might decrease kisspeptin levels directly through a negative feedback mechanism, since we found no relationship between changes in kisspeptin levels and changes in anthropometric or metabolic parameters or in leptin levels. Further studies are required to corroborate this hypothesis.

Author Contributions: O.G.-P., L.C., and A.C. designed the study, recruited the patients, and wrote the manuscript. R.C. and S.E.-C. also recruited some patients and contributed to additional versions of the manuscript. R.P. obtained and stored all the blood samples and contributed to the methodology section of the manuscript. N.A. contributed to laboratory tasks and to methodology section. M.R. contributed to the final version of the manuscript. All authors have read and agreed to the published version of the manuscript.

Funding: This research was funded by Instituto de Salud Carlos III and Fondo Europeo de Desarrollo Regional "Feder: Otra manera de hacer Europa" grant number PI18/00734. Also by Fundació Parc Taulí, grant number (CIR2018/001).

Institutional Review Board Statement: The study was conducted according to the guidelines of the Declaration of Helsinki, and approved by the Ethics Committee "Comitè d'Ètica d'Investigació amb medicaments" (CEIm) del Parc Taulí (Ethical Committee approval on 4 July 2019—Code CIR2018/001).

Informed Consent Statement: Informed consent was obtained from all subjects involved in the study.

Data Availability Statement: Data supporting reported results can be found in Parc Taulí server (contact jcoliva@tauli.cat or the corresponding author acaixas@tauli.cat).

Acknowledgments: We thank the Associació Catalana de Síndrome de Prader-Willi for crowdfunding and all the patients and their families for kindly agreeing to participate. We also thank Neus Gómez-Gerique for kisspeptin determinations and Joan Carles Oliva for data analysis.

Conflicts of Interest: The authors have no conflict of interest.

\section{References}

1. Gahete, M.D.; Vázquez-Borrego, M.C.; Martínez-Fuentes, A.J.; Tena-Sempere, M.; Castaño, J.P.; Luque, R.M. Role of the Kiss1/Kiss1r System in the Regulation of Pituitary Cell Function. Mol. Cell. Endocrinol. 2016, 438, 100-106. [CrossRef] [PubMed]

2. Castellano, J.M.; Tena-Sempere, M. Metabolic Regulation of Kisspeptin. Adv. Exp. Med. Biol. 2013, 784, 363-383. [CrossRef]

3. Allaway, H.C.M.; Southmayd, E.A.; De Souza, M.J. The Physiology of Functional Hypothalamic Amenorrhea Associated with Energy Deficiency in Exercising Women and in Women with Anorexia Nervosa. Horm. Mol. Biol. Clin. Investig. 2016, 25, 91-119. [CrossRef]

4. George, J.T.; Millar, R.P.; Anderson, R.A. Hypothesis: Kisspeptin Mediates Male Hypogonadism in Obesity and Type 2 Diabetes. Neuroendocrinology 2010, 91, 302-307. [CrossRef] [PubMed]

5. Castellano, J.M.; Bentsen, A.H.; Mikkelsen, J.D.; Tena-Sempere, M. Kisspeptins: Bridging Energy Homeostasis and Reproduction. Brain Res. 2010, 1364, 129-138. [CrossRef] [PubMed] 
6. Dudek, M.; Ziarniak, K.; Sliwowska, J.H. Kisspeptin and Metabolism: The Brain and Beyond. Front. Endocrinol. $2018,9,145$. [CrossRef] [PubMed]

7. Cassidy, S.B.; Schwartz, S.; Miller, J.L.; Driscoll, D.J. Prader-Willi Syndrome. Genet. Med. 2012, 14, 10-26. [CrossRef]

8. Butler, M.G. Prader-Willi Syndrome: Obesity Due to Genomic Imprinting. Curr. Genomics 2011, 12, 204-215. [CrossRef] [PubMed]

9. Moix Gil, E.; Giménez-Palop, O.; Caixàs, A. Treatment with Growth Hormone in the Prader-Willi Syndrome. Endocrinol. Diabetes Nutr. 2018, 65, 229-236. [CrossRef] [PubMed]

10. Novell-Alsina, R.; Esteba-Castillo, S.; Caixàs, A.; Gabau, E.; Giménez-Palop, O.; Pujol, J.; Deus, J.; Torrents-Rodas, D. Compulsions in Prader-Willi Syndrome: Occurrence and Severity as a Function of Genetic Subtype. Actas Esp. Psiquiatr. 2019, 47, 79-87. [PubMed]

11. Guinovart, M.; Coronas, R.; Caixàs, A. Psychopathological Disorders in Prader-Willi Syndrome. Endocrinol. Diabetes Nutr. 2019, 66, 579-587. [CrossRef]

12. Caixàs, A.; Blanco-Hinojo, L.; Pujol, J.; Deus, J.; Giménez-Palop, O.; Torrents-Rodas, D.; Coronas, R.; Novell, R.; Esteba-Castillo, S. Altered Gesture Imitation and Brain Anatomy in Adult Prader-Willi Syndrome Patients. J. Int. Neuropsychol. Soc. 2021, 1-13. [CrossRef] [PubMed]

13. Sanchez-Ortiga, R.; Klibanski, A.; Tritos, N.A. Effects of Recombinant Human Growth Hormone Therapy in Adults with Prader-Willi Syndrome: A Meta-Analysis. Clin. Endocrinol. 2012, 77, 86-93. [CrossRef]

14. Grugni, G.; Sartorio, A.; Crinò, A. Growth Hormone Therapy for Prader-Willi Syndrome: Challenges and Solutions. Ther. Clin. Risk Manag. 2016, 12, 873-881. [CrossRef] [PubMed]

15. Lafortuna, C.L.; Minocci, A.; Capodaglio, P.; Gondoni, L.A.; Sartorio, A.; Vismara, L.; Rizzo, G.; Grugni, G. Skeletal Muscle Characteristics and Motor Performance after 2-Year Growth Hormone Treatment in Adults with Prader-Willi Syndrome. J. Clin. Endocrinol. Metab. 2014, 99, 1816-1824. [CrossRef]

16. Myers, S.E.; Whitman, B.Y.; Carrel, A.L.; Moerchen, V.; Bekx, M.T.; Allen, D.B. Two Years of Growth Hormone Therapy in Young Children with Prader-Willi Syndrome: Physical and Neurodevelopmental Benefits. Am. J. Med. Genet. 2007, 143, 443-448. [CrossRef]

17. Deal, C.L.; Tony, M.; Höybye, C.; Allen, D.B.; Tauber, M.; Christiansen, J.S. 2011 Growth Hormone in Prader-Willi Syndrome Clinical Care Guidelines Workshop Participants GrowthHormone Research Society Workshop Summary: Consensus Guidelines for Recombinant Human Growth Hormone Therapy in Prader-Willi Syndrome. J. Clin. Endocrinol. Metab. 2013, 98, E1072-E1087. [CrossRef] [PubMed]

18. Yuen, K.C.J.; Tritos, N.A.; Samson, S.L.; Hoffman, A.R.; Katznelson, L. American association of Clinical Endocrinologists and American Collage of Endocrinology disease state clinical review: Update on growth hormone stimulation testing and proposed revised cut-point for the glucagon stimulation test in the diagnosis of adult growth hormone deficiency. Endocr. Pract. 2016, 22, 1235-1244. [CrossRef]

19. Casamitjana, L.; Giménez-Palop, O.; Corripio, R.; Pareja, R.; Berlanga, E.; Rigla, M.; Oliva, J.C.; Caixàs, A. Glucagon Stimulation Test to Assess Growth Hormone Status in Prader-Willi Syndrome. J. Endocrinol. Invest. 2021, 44, 621-629. [CrossRef]

20. Matthews, D.R.; Hosker, J.P.; Rudenski, A.S.; Naylor, B.A.; Treacher, D.F.; Turner, R.C. Homeostasis Model Assessment: Insulin Resistance and Beta-Cell Function from Fasting Plasma Glucose and Insulin Concentrations in Man. Diabetologia 1985, $28,412-419$. [CrossRef]

21. Hestiantoro, A.; Astuti, B.P.K.; Muharam, R.; Pratama, G.; Witjaksono, F.; Wiweko, B. Dysregulation of Kisspeptin and Leptin, as Anorexigenic Agents, Plays Role in the Development of Obesity in Postmenopausal Women. Int. J. Endocrinol. 2019, 2019, 1347208. [CrossRef]

22. Pita, J.; Barrios, V.; Gavela-Pérez, T.; Martos-Moreno, G.Á.; Muñoz-Calvo, M.T.; Pozo, J.; Rovira, A.; Argente, J.; Soriano-Guillén, L. Circulating Kisspeptin Levels Exhibit Sexual Dimorphism in Adults, Are Increased in Obese Prepubertal Girls and Do Not Suffer Modifications in Girls with Idiopathic Central Precocious Puberty. Peptides 2011, 32, 1781-1786. [CrossRef] [PubMed]

23. Sitticharoon, C.; Mutirangura, P.; Chinachoti, T.; Iamaroon, A.; Triyasunant, N.; Churintaraphan, M.; Keadkraichaiwat, I.; Maikaew, P.; Sririwichitchai, R. Associations of Serum Kisspeptin Levels with Metabolic and Reproductive Parameters in Men. Peptides 2021, 135, 170433. [CrossRef]

24. Sitticharoon, C.; Boonpuan, V.; Mitrpant, C. Determination of KISS1, KISS1R and Kisspeptin in Fat Tissue of Normal Weight and Obese Humans and Correlations between Serum Kisspeptin and Leptin. Siriraj Med. J. 2013, 65, 112-116.

25. Sitticharoon, C.; Sukharomana, M.; Likitmaskul, S.; Churintaraphan, M.; Maikaew, P. Increased High Molecular Weight Adiponectin, but Decreased Total Adiponectin and Kisspeptin, in Central Precocious Puberty Compared with Aged-Matched Prepubertal Girls. Reprod. Fertil. Dev. 2017, 29, 2466-2478. [CrossRef] [PubMed]

26. Latif, R.; Rafique, N. Serum Kisspeptin Levels across Different Phases of the Menstrual Cycle and Their Correlation with Serum Oestradiol. Neth. J. Med. 2015, 73, 175-178.

27. Sukhbaatar, U.; Kanasaki, H.; Mijiddorj, T.; Oride, A.; Hara, T.; Yamada, T.; Kyo, S. Expression of GnRH and Kisspeptin in Primary Cultures of Fetal Rat Brain. Reprod. Sci. 2017, 24, 227-233. [CrossRef]

28. Zhu, H.J.; Li, S.J.; Pan, H.; Li, N.; Zhang, D.X.; Wang, L.J.; Yang, H.B.; Wu, Q.; Gong, F.Y. The Changes of Serum Leptin and Kisspeptin Levels in Chinese Children and Adolescents in Different Pubertal Stages. Int. J. Endocrinol. 2016, 2016, 6790794. [CrossRef] 
29. Andreozzi, F.; Mannino, G.C.; Mancuso, E.; Spiga, R.; Perticone, F.; Sesti, G. Plasma Kisspeptin Levels Are Associated with Insulin Secretion in Nondiabetic Individuals. PLOS ONE 2017, 12, e0179834. [CrossRef]

30. Bacopoulou, F.; Lambrou, G.I.; Rodanaki, M.-E.; Stergioti, E.; Efthymiou, V.; Deligeoroglou, E.; Markantonis, S.L. Serum Kisspeptin Concentrations Are Negatively Correlated with Body Mass Index in Adolescents with Anorexia Nervosa and Amenorrhea. Hormones 2017, 16, 33-41. [CrossRef]

31. Höybye, C. Endocrine and Metabolic Aspects of Adult Prader-Willi Syndrome with Special Emphasis on the Effect of Growth Hormone Treatment. Growth Horm. IGF Res. 2004, 14, 1-15. [CrossRef] [PubMed]

32. Sode-Carlsen, R.; Farholt, S.; Rabben, K.F.; Bollerslev, J.; Schreiner, T.; Jurik, A.G.; Frystyk, J.; Christiansen, J.S.; Höybye, C. Growth Hormone Treatment for Two Years Is Safe and Effective in Adults with Prader-Willi Syndrome. Growth Horm. IGF Res. 2011, 21, 185-190. [CrossRef]

33. Wolfe, A.; Hussain, M.A. The Emerging Role(s) for Kisspeptin in Metabolism in Mammals. Front. Endocrinol. 2018, 9, 184. [CrossRef] [PubMed]

34. Friedman, J.M.; Halaas, J.L. Leptin and the Regulation of Body Weight in Mammals. Nature 1998, 395, 763-770. [CrossRef]

35. Harvey, J. Leptin Regulation of Neuronal Morphology and Hippocampal Synaptic Function. Front. Synaptic Neurosci. $2013,5,3$. [CrossRef] [PubMed]

36. Guzmán, A.; Hernández-Coronado, C.G.; Rosales-Torres, A.M.; Hernández-Medrano, J.H. Leptin Regulates Neuropeptides Associated with Food Intake and GnRH Secretion. Ann. Endocrinol. 2019, 80, 38-46. [CrossRef] [PubMed]

37. Höybye, C.; Barkeling, B.; Espelund, U.; Petersson, M.; Thorén, M. Peptides Associated with Hyperphagia in Adults with Prader-Willi Syndrome before and during GH Treatment. Growth Horm. IGF Res. 2003, 13, 322-327. [CrossRef]

38. Myers, S.E.; Davis, A.; Whitman, B.Y.; Santiago, J.V.; Landt, M. Leptin Concentrations in Prader-Willi Syndrome before and after Growth Hormone Replacement. Clin. Endocrinol. 2000, 52, 101-105. [CrossRef]

39. Holmes, D. Metabolism: Kisspeptin Signalling Linked to Obesity. Nat. Rev. Endocrinol. 2014, 10, 511. [CrossRef]

40. Izzi-Engbeaya, C.; Comninos, A.N.; Clarke, S.A.; Jomard, A.; Yang, L.; Jones, S.; Abbara, A.; Narayanaswamy, S.; Eng, P.C.; Papadopoulou, D.; et al. The Effects of Kisspeptin on $\beta$-Cell Function, Serum Metabolites and Appetite in Humans. Diabetes Obes. Metab. 2018, 20, 2800-2810. [CrossRef] 